NOTE

\title{
Larval energy metabolism and physiological variability in the Asian shore crab Hemigrapsus sanguineus
}

\author{
Adam G. Marsh*, Sahrye Cohen ${ }^{* *}$, Charles E. Epifanio \\ College of Marine Studies, University of Delaware, Lewes, Delaware 19958, USA
}

\begin{abstract}
Larvae of the Asian shore crab Hemigrapsus sanguineus were reared in the laboratory during zoeal development (Stages I to $\mathrm{V}, \sim 15 \mathrm{~d}$ at $25^{\circ} \mathrm{C}$ and $30 \%$ S). Measurements of respiration rates, lactate dehydrogenase activity (LDH) and total protein content were made daily on individual larvae $(\mathrm{n}=181)$ in order to assess the level of individual variance in energy metabolism during development. On average, zoeal development in $H$. sanguineus was estimated to require $43.8 \mathrm{~J}$ of metabolic energy to reach a megalope stage; however, the level of individual variance in metabolic rates resulted in a range of 23.8 to $67.9 \mathrm{~J} \mathrm{(} 3$-fold difference). LDH specific activities also evidenced a wide range in individual values during development (12 to $785 \mu \mathrm{U} \mu^{-1}$ protein). Although respiration rates were correlated with LDH specific activity $\left(\mathrm{r}^{2}=0.628\right)$, it is more interesting to note the negative correlation between the variance in these measurements $\left(r^{2}=0.796\right)$, indicating a substantial degree of individual differences in metabolic activities among these larvae. At present, phenotypic variations in physiological rate processes are not considered in life-history models of larval development, which could be an important variable determining the survival and dispersal of a larval cohort.
\end{abstract}

KEY WORDS: Larvae $\cdot$ Physiology $\cdot$ Life history $\cdot$ Hemigrapsus sanguineus $\cdot$ Lactate dehydrogenase $\cdot$ Respiration

Resale or republication not permitted without written consent of the publisher

Larval development is an important component of most life-history strategies in marine invertebrates. Recent efforts to model the energy requirements of different developmental strategies (McEdward 1997, Hentschel 1999) have indicated the significant impact that energy utilization can have on the size and age of a larva at metamorphosis. Although there has been a general interest in describing the energy requirements of larval development (review Moreno \& Hoegh-Guldberg 1999), technical problems with making accurate

\footnotetext{
*E-mail: amarsh@udel.edu

** Present address: Department of Biology, Tufts University, Medford, Massachusetts 02155, USA
}

measurements of respiration rates on small embryos and larvae leave some of these estimates doubtful, particularly those obtained with microelectrode techniques (as discussed in Hoegh-Guldberg \& Manahan 1995, Marsh \& Manahan 1999). Despite the importance of knowing the specific energy costs of development for different embryos and larvae, our theoretical constructs of developmental energetics in marine invertebrates currently have limited empirical data for support.

One of the shortcomings of measuring biochemical and physiological rate processes in small embryos and larvae is that many individuals (10s to 1000 s) must be pooled for a single measurement. The result is that most of the published data on larval physiology represent average responses across an array of individual genotypes (e.g., Marsh et al. 1999, Marsh \& Manahan 2000). In considering the selective advantages or disadvantages of different larval types for a species' life history, it is generally not the average level of larval performance that will be subjected to the most intense selective pressures, but rather the individual extremes about that mean response level. In stable environments, selection forces will favor an average physiological phenotype, but in variable environments, the outlier physiological phenotypes (i.e., faster or slower developmental rates, bigger or smaller larvae) may become important in determining the survival or dispersal success of a larval cohort. In the literature, current estimates of developmental energetics represent mean estimates of larval performance and do not present the potential minimum and maximum rates of energy utilization that may exist within a larval cohort.

To assess individual larval performance, we present a series of microassays that are appropriate for making simultaneous measurements of respiration rate, protein content, and lactate dehydrogenase activity (LDH) on single zoea larvae of the Asian shore crab Hemigrapsus sanguineus. This approach allows for specific 
determination of the individual variance associated with metabolic rates and energy utilization during zoeal development. Minimum and maximum estimates of energy utilization demonstrate a wide range in the metabolic activity of individuals, which could impact the metamorphic age (dispersal time) and size (growth) of larvae in the field.

Materials and methods. Larval rearing and handling: Gravid Hemigrapsus sanguineus were collected in the intertidal zone from a breakwater at Roosevelt Inlet, Delaware Bay, Delaware, USA. The females were maintained in laboratory culture chambers with filtered seawater maintained at $25^{\circ} \mathrm{C}, 30 \%$ (S), and $14: 10 \mathrm{~h}$ light:dark photoperiod until spawning (culturing methodology and zoeal development of $H$. sanguineus has been previously described by Epifanio et al. 1998). When the Stage I zoea larvae hatched from the egg masses carried by a female, the larvae were transferred to culture dishes and maintained under the same conditions, with water changes every $48 \mathrm{~h}$ and an ad libitum ration of live Artemia sp. nauplii. A total of 4 broods from different females were used to assemble the daily time series for the $2 \mathrm{wk}$ period required to develop from a Stage I zoea larvae to a megalopa stage. For each sample, 50 individuals were removed from the main culture bowls and gently rinsed on $80 \mu \mathrm{m}$ mesh screening by 2 successive transfers between bowls with clean filtered seawater (FSW, $0.2 \mu \mathrm{m})$. No mortality was observed during this handling. The zoeal cultures were highly synchronous in their development and on each sampling day 10 individual zoeae at the same stage were selected for the physiological measurements. A total of 181 individuals were analyzed in this study.

Oxygen consumption: A total of 10 individuals were removed from the final FSW wash and placed individually into small (400 $\mu$ l) respiration vials for end-point determinations of oxygen consumption of each zoea (after Marsh \& Manahan 1999). The respiration vials function as $\mu$ BOD bottles with ground-glass stoppers to ensure a gas-tight fit. Zoea larvae were sealed in the vials (without air bubbles) and incubated at $21^{\circ} \mathrm{C}$ in a temperature-controlled water bath for 2 to $4 \mathrm{~h}$, depending on their metabolic rate. Oxygen concentrations were measured in the vials (as well as in control blanks without zoea larvae) using an optical fluorescent detection system (optrode; Ocean-Optics, Dunedin, FL, USA) similar in practice to that described in Stokes \& Somero (1999). The optrode was controlled by a laptop computer and calibrated using oxygen-saturated and deoxygenated FSW standards using the manufacturer's software (001Sensor v.2). The calibration of the optrode was checked against voltammeric readings of dissolved oxygen concentrations using a custom electrode (Brendel \& Luther 1995) on several occasions to verify that the calibration was accurate.
LDH and protein assays: Total LDH activities (EC 1.1.1.27) were assayed using the spectrophotometric absorbance of reduced $\beta$-nicotinamide adenine dinucleotide (NADH) in a microassay protocol adapted from a standard LDH assay (Long 1975). Each individual zoea larva was transferred from the $\mu B O D$ vials immediately after the respiration measurements to a chilled depression glass-slide. The FSW was removed with a pipette and $98 \mu$ of homogenization buffer was added (20 mM Tris, pH 8.5). A micro glass pestle was then used to homogenize each larva individually in the separate depressions on the glass-slides. The $98 \mu \mathrm{l}$ homogenate was then transferred to a 96-well microtiter plate. The reaction was initiated with the addition of $\beta$-NAD ${ }^{+}(560 \mu \mathrm{M}$ final concentration) and then L-lactate (40 mM final concentration) (Long 1975). The increase in absorbance at $340 \mathrm{~nm}$ was then followed in a plate-reading spectrophotometer ( $\mu$ Quant, BioTek, Winooski, VT, USA) for 1 to $3 \mathrm{~h}$ (depending on developmental age) with measurements at 5 min intervals at $21^{\circ} \mathrm{C}$. Reaction rates were calculated only over a time interval where the change in optical density was linear with respect to time, and generally limited to only the first 1 to $2 \mathrm{~h}$. Although this assay period is much longer than normal, the reaction rates were linear for up to $4 \mathrm{~h}$. During this extended time there was no evidence of enzyme breakdown or inactivation, even in the absence of protease inhibitors in the extraction buffer. A preliminary series of assays was run to establish that these substrate concentrations were saturating. Reaction conditions were verified to be saturating for $V_{\max }$ measurements by using 0.2 to $20 \mathrm{mU}$ of a standard LDH (type XXXV porcine heart; $1 \mathrm{U}$ equals the conversion of $1 \mu \mathrm{mol}$ lactate to pyruvate $\mathrm{min}^{-1}$ ). In addition, substrate concentrations were also doubled in preliminary assays using Stage $\mathrm{V}$ zoeae to verify that the reaction rates were saturated (the highest total activity level measured in a larva during this study was $2 \mathrm{mU}$ ). Test assays in the absence of L-lactate did not reveal any measurable background rates of $\beta-\mathrm{NAD}^{+}$ reduction during this time course.

Immediately after the LDH assay was completed, the protein content in each well was directly measured in the microtiter plates with a Bradford assay using a commercially available Coomassie reagent (Pierce Biochemicals, Rockford, IL, USA). A series of protein standard concentrations of bovine serum albumin (1 to $25 \mu \mathrm{g} \mathrm{ml}^{-1}$ ) was added to 12 wells on the plate (6 concentrations $\times 2$ duplicates) and then an equal volume of diluted Coomassie reagent $(100 \mu \mathrm{l})$ was added to both the standards and samples. The wells were mixed and the plate was returned to the spectrophotometer to measure the optical density at $595 \mathrm{~nm}$. In this way, the potential for methodological variability due to sample handling during homogenization and pipette transfer 
was minimized because both the protein and the LDH assays were conducted on the same homogenate aliquots. Although handling errors are bound to exist in any sample protocol, these errors will cancel out when calculating the ratio of the measured LDH activity to the measured protein content (protein specific activity of $\mathrm{LDH}_{i} \mu \mathrm{mol}$ lactate $\mathrm{min}^{-1} \mathrm{mg}^{-1}$ protein). Here, any handling errors associated with the sample protocol will be equivalent for both the numerator (LDH activity) and denominator (protein content) because these measurements were made on the same sample volumes in the same reaction wells.

All physiological measurements were made at $21^{\circ} \mathrm{C}$ (room temperature). The lack of a temperature controlblock in the plate-reading spectrophotometer dictated that these measurements be made at $21^{\circ} \mathrm{C}$ and not at the temperature at which the larvae were cultured $\left(25^{\circ} \mathrm{C}\right)$. Although the rates determined at $21^{\circ} \mathrm{C}$ are likely to be $\sim 25 \%$ lower than at $25^{\circ} \mathrm{C}$ (assuming a $Q_{10}$ of 2.0), the magnitude of the variance between individual measurements is likely to be the same.

Data analysis: LDH activities are presented as $\mu \mathrm{U}$ because of the low activity present in an individual larva $(1 \mu \mathrm{U}=$ the conversion of 1 pmol lactate to pyruvate $\min ^{-1}$ ). The regression routines available in SigmaStat 2.0 (Jandel Scientific, SPSS Inc., Chicago, IL, USA) were used for all data analyses presented. No differences between zoea larvae of different broods were evident in any of the analyses; consequently all individual measurements are treated independently without a blocking design for the different females.

Results. During development, there is a large increase in the specific activity of LDH (measured as $V_{\text {maxi }}$ Fig. 1a). A similar developmental pattern of $\mathrm{LDH}$ specific activities during zoeal development has been reported for Cancer irroratus (Sastry \& Ellington 1978). Converting the data of Sastry \& Ellington (1978) to $\mu \mathrm{U} \mu \mathrm{g}^{-1}$ protein we see that LDH specific activities for Stage I to IV zoea of $C$. irroratus range from a mean of

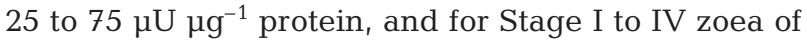
Hemigrapsus sanguineus our values range from 50 to $100 \mu \mathrm{U} \mu \mathrm{g}^{-1}$ protein for individual larvae (Fig. 1a). However, the Stage V zoea show a large difference in their LDH activities, with $H$. sanguineus rapidly increasing to $\sim 450 \mu \mathrm{U} \mu^{-1}$ protein, while C. irroratus only shows a smaller increase at the megalopa stage to $\sim 100 \mu \mathrm{U} \mu \mathrm{g}^{-1}$ protein.

Total metabolic rates of the zoea larval stages of H. sanguineus (Fig. 1b) exhibit a temporal pattern that appears to parallel the temporal change in LDH activity. There is a strong correlation between these measurements $\left(\mathrm{r}^{2}=0.858, \mathrm{p}<0.001\right.$; not plotted $)$; however, this correlation is confounded by the fact that the response levels plotted in Fig. 1 are mean values of 10 to 20 individual measurements. Most studies of physi-

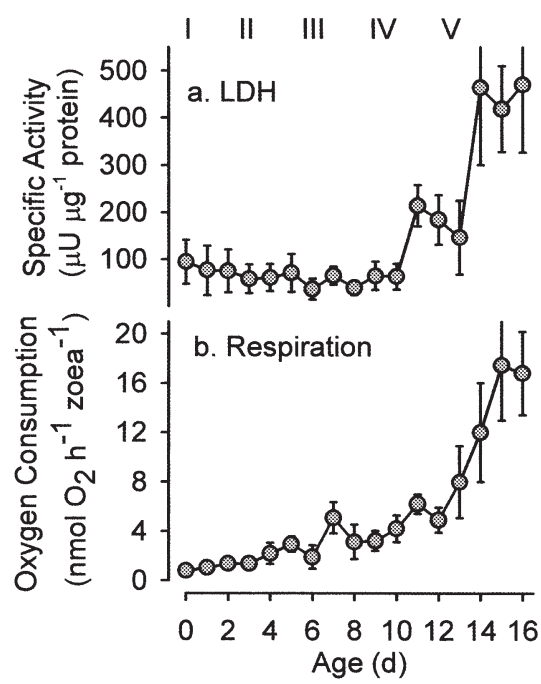

Fig. 1. Hemigrapsus sanguineus. Specific activities of (a) lactate dehydrogenase (LDH) and (b) respiration rates during zoeal development (means $\pm 1 \mathrm{SD}$ ). On each day of development, respiration rates were measured on 10 to 20 individuals, and immediately afterward, the specific activity of LDH was assessed in each of those individuals. Roman numerals at the top indicate the first day at which a zoeal stage (I to V) was reached

ological rate processes in larvae contain such confounding 'pooling' effects because of the general necessity of combining many individuals in order to obtain sufficient biomass for a particular measurement. In general, the variance associated with most of these measurements in the literature is low simply because they are usually generated by taking the mean of a number of replicates, with each replicate itself a 'mean' response of 10 s to 1000 s of individuals. Instead of looking at a 'pooled' correlation between LDH and respiration, we are interested in the correlation between these parameters at the level of individual larvae.

Although the overall error rates in Fig. 1 are small about the means (SEs $<15 \%$; $>10$ individuals), there is a substantial level of sample variance when looking at the individual measurements of protein content, LDH activity and oxygen consumption (Fig. 2). Protein content shows the greatest differences between individual zoeae during development, suggesting large differences in feeding rates (and subsequent body growth). LDH activities are relatively low and variable during the first week of zoea development, but rapidly increase with a concomitant decline in the level of individual differences during the last week of development. Oxygen consumption rates remain low with little individual variance during early development of zoeae, but rapidly increase during the last days of development with an increase in the variance of individual metabolic rates. The concomitant increase in LDH activity and oxygen consumption (Fig. 1) suggests that a large increase in 


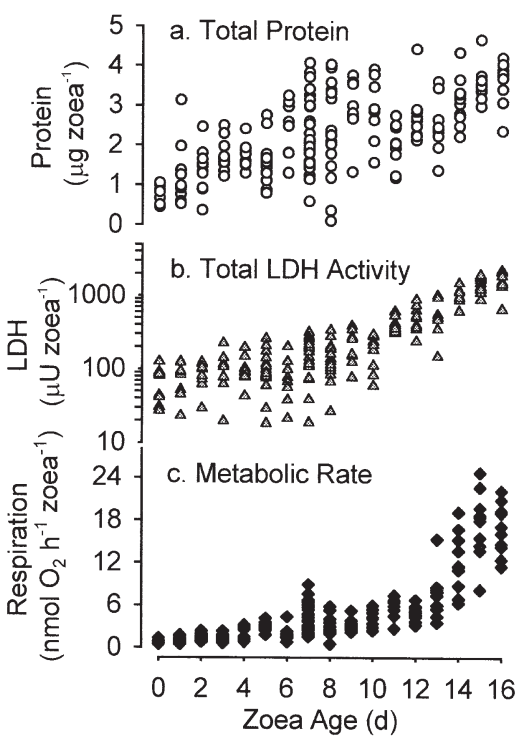

Fig. 2. Hemigrapsus sanguineus. Simultaneous measurements of (a) total protein, (b) LDH activity ( $\log _{10}$ scale) and (c) metabolic rates for individual zoeal larvae. On each day of development, 10 to 20 individuals were used for near-simultaneous measurements of these 3 physiological parameters. Note that each data point in a panel represents an individual zoea larva for which corresponding measurements exists in the other 2 panels $(\mathrm{n}=181$ individuals $)$

potential anaerobic metabolic activity (such as burstswimming capacity; Forward 1986) significantly influences the total metabolic rate of late stage zoea larvae; however, the interrelationship of these parameters is less evident when considering the actual level of individual variance (Fig. 2). Here, although LDH activities are highest for a Stage V zoea larva (Fig. 2b), there are still large differences in total oxygen consumption rates between individuals (Fig. 2c).

Direct correlations of these individual measurements $(n=181)$ produced a more detailed perspective on their interrelationships. A surprising result is the absence of a strong correlation between protein content and the $V_{\text {max }}$ measurements of LDH activity $\left(\mathrm{r}^{2}=0.395\right.$; Fig. 3a). As a standard metabolic enzyme, one would assume that total LDH content would be highly conserved among individuals and, thus, could almost function as a proxy measurement of biomass. Differences in individual feeding rates are likely to result in differences in nutrient storage in these larvae and, thus, lead to a higher variance in individual protein content. However, there is a high correlation $\left(\mathrm{r}^{2}=0.628 ; \mathrm{p}<0.001\right)$ between larval respiration rates and LDH protein-specific activities (total LDH activity normalized to total protein content; Fig. 3b). This regression takes the standard power model used to scale respiration rates $(R)$ to body mass $(M): R=a M^{b}$ (see Heusner 1991). The implication is that LDH specific activities serve as a proxy of organismal size (cf. Fig. 3a) and are correlated to respiration rates. Biomass scaling of metabolic rates in embryos and larvae (see Jørgensen \& Vernberg 1982) are difficult because of the presence of nutrient storage reserves (Marsh \& Manahan 2000). In Hemigrapsus sanguineus larvae, LDH protein-specific activities are likely to be related to the 'metabolically active' fraction of biomass in these larvae and, thus, show some correlation to metabolic rates. In an advanced zoeal stage, we can also see that LDH specific activities

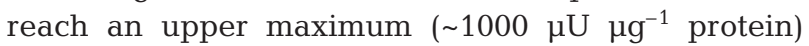
even though respiration rates continued to increase in some individuals.

To assess the relationship of the level of individual variance between protein content, LDH activity and oxygen consumption, daily means and their corresponding variances were calculated from the individual measurements (as in Fig. 1). A strong positive correlation exists between the individual daily variances in protein content and oxygen consumption $\left(\mathrm{r}^{2}=0.707\right.$, $\mathrm{p}<0.001$; Fig 4a). This correlation indicates that a large component of the variance we have observed in these measures is a direct result of inter-individual variability in both larval growth (protein content) and larval metabolic rates (see 'Discussion'). In contrast, there is a strong negative correlation between the individual daily variances in LDH specific activities and oxygen consumption $\left(\mathrm{r}^{2}=0.796, \mathrm{p}<0.001\right.$; Fig. $\left.4 \mathrm{~b}\right)$. Although the daily means are positively correlated (Fig. 1), their variances exhibit opposite trends; as the
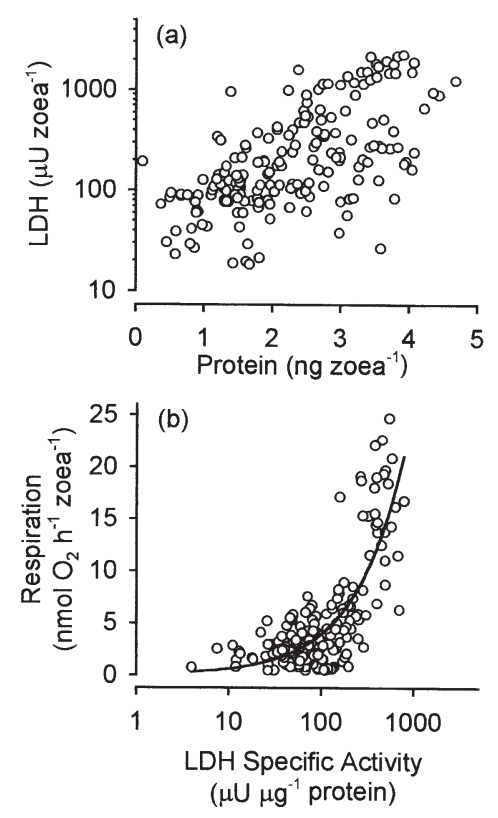

Fig. 3. Hemigrapsus sanguineus. Relationship between (a) LDH activity and protein content of zoea larvae and (b) metabolic rates and LDH specific activities described by the regression model: $y=0.095 x^{0.811} ; r^{2}=0.628$ 


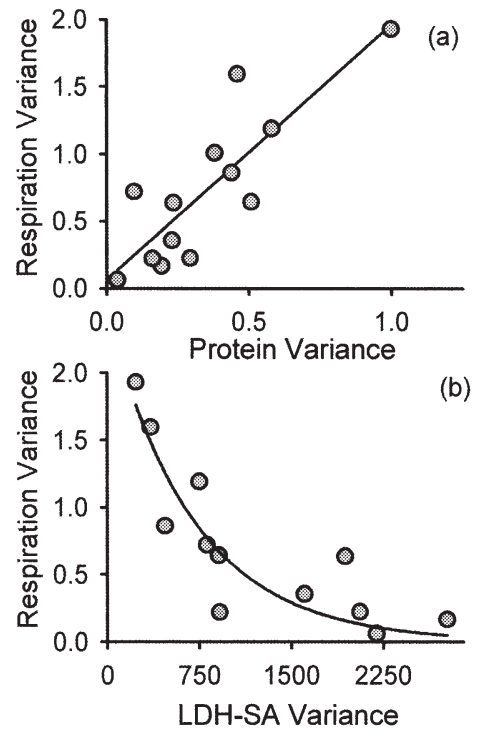

Fig. 4. Hemigrapsus sanguineus. Individual measurements for each day of development were used to calculate daily mean in protein content, LDH activity and oxygen consumption, with a corresponding estimate of the variance associated with that mean value. (a) The relationship between the variance in metabolic rate measurements ( $\mathrm{pmol} \mathrm{O}_{2} \mathrm{~h}^{-1} \mathrm{zoea}^{-1}$ ) and the variance in protein content $\left(\mu \mathrm{g}\right.$ zoea $\left.^{-1}\right)$ can be described by a linear regression model: $y=0.066+1.897 x ; r^{2}=0.707$. (b) The variance in metabolic rates is inversely correlated to the variance in LDH specific activities $\left(\mu \mathrm{U} \mu \mathrm{g}^{-1}\right.$ protein) as described by the regression model: $y=2.46 \mathrm{e}^{[-0.0014 x]} ; \mathrm{r}^{2}=0.796$

level of individual variance in LDH specific activities declines during the latter part of zoeal development, the individual variance in respiration rates increases. This suggests that LDH specific activities do not play a large role in determining the metabolic rate of zoeae, and that the correlation observed between both the mean and individual levels of LDH and respiration (Figs. 1 \& 3b, respectively) are secondary or coincidental, i.e. resulting from their correlation with other variables, such as individual size or mass.

Discussion. We know that developmental processes are impacted by environmental variables, primarily through affecting 2 characteristics of larval development: size and age at metamorphosis. These parameters play an important role in current models of life-history strategies (Havenhand 1995, McEdward 1997, Pechenik et al. 1998, Hentschel 1999, Pechenik 1999), and we know that there is considerable variability in the determinants of larval size and age at metamorphosis in marine invertebrates (Hart 1995, Emlet \& HoeghGuldberg 1997, Hare \& Cowen 1997, McEdward \& Morgan 2001). In addition to the known environmental determinants of larval age and size at metamorphosis, individual genotype can also play a role in determining the physiological performance, and thus have an additional impact on developmental rates (age) and devel- opmental growth (size) of a larva (Hedgecock et al. 1996, Hawkins \& Day 1999).

The zoea larvae of Hemigrapsus sanguineus are released from a maternal brood into coastal environments, where they feed and continue development in the water column until reaching a megalopa stage (Epifanio et al. 1998). Although larval dispersal is primarily determined by local current conditions (Epifanio \& Garvine 2001), under vertically sheared flows swimming behaviors in zoea larvae can alter their vertical position in the water column and change the current regime to which they are exposed. In addition, burst-swimming capacities in zoeae are important for predator avoidance (Forward 1986). We have examined the overall changes in metabolic energy utilization associated with zoea development by measuring total oxygen consumption rates, in addition to looking at the ontogenetic changes in lactate dehydrogenase activities as an index of burst-swimming potential (short-term anaerobic glycolysis; Holland et al. 1997). Overall, our LDH measurements in $H$. sanguineus were in close agreement with the values reported during development in zoeae of Cancer irroratus (Sastry \& Ellington 1978).

Our approach to making these measurements on single larvae was designed to provide a data set from which we could directly correlate LDH activities with metabolic rates during larval development. The individual means $( \pm \mathrm{SD})$ plotted in Fig. 1 suggest a tight correlation between LDH specific activities and larval respiration rates; however, there is a large amount of individual variance in the metabolic and biochemical measurements of each zoea (Fig. 2). Traditionally, one would assume that this level of variance was a result of methodological problems from working with small individuals. Indeed, measurement precision is one of the primary necessities for pooling embryos and larvae into larger samples. However, the inter-sample variance will decrease as the number of individuals increases in the pooled samples, because the resultant measurements represent an 'average' over an increasingly larger scope.

The correlation between the variance in individual respiration rates with both the variance in zoea protein contents $\left(r^{2}=0.707\right.$; Fig. $\left.4 \mathrm{a}\right)$ and zoea LDH specific activities $\left(r^{2}=0.796\right.$; Fig. $\left.4 \mathrm{~b}\right)$ indicates that a large portion of the individual sample variability shown in Fig. 2 is not attributable to methodological imprecision, but rather to a source of biological variance in the metabolic and biochemical activities of these individual zoea larvae. This is because the measurements of respiration rates were conducted independently of the post-processing for the protein and LDH assays. The correlation between the variances in these measurements must share a common source of variability prior 
to the processing of these samples, i.e. a source of variability introduced at the physiological level of the individual zoea larvae.

It is not surprising that larvae have different metabolic rates, but it is interesting to note how large those differences may become. On average, zoeal development in Hemigrapsus sanguineus was estimated to have consumed at least $43.8 \mathrm{~J}$ of metabolic energy to reach a megalopa stage (from the respiration rate measurements at $21^{\circ} \mathrm{C}$, using an average oxyenthalpic equivalent of $484 \mathrm{~kJ} \mathrm{~mol}^{-1} \mathrm{O}_{2}$; Gnaiger 1983, Marsh \& Manahan 1999); however, the level of individual variance in metabolic rates could potentially result in a range of 23.8 to $67.9 \mathrm{~J}$. These estimates were obtained by integrating the daily minimum and maximum respiration rate measurements through development, and indicate that these zoea larvae could show an almost 3 -fold difference in metabolic energy utilization during development. In life-history models of larval energetics, this is a significant difference in energy utilization between what we would normally describe as 'identical' larvae. In fact, estimates of metabolic energy utilization between different non-feeding and feeding larval forms (in closely related species) show an equivalent difference in developmental energetics $(<3$-fold; Hoegh-Guldberg \& Emlet 1997, Moreno \& HoeghGuldberg 1999) as estimated here between individual zoea of $H$. sanguineus. Future experiments will be required to follow the metabolic rates of single zoeae throughout development to ascertain the true variance in total developmental energetics within this species.

Because LDH is one of the major enzymatic regulatory points controlling the flux of metabolites between aerobic and anaerobic glycolysis, the negative correlation in Fig. 4b seems counter-intuitive to a general assumption that the level of LDH should be a proximal factor in setting individual metabolic rates. It has been an unstated goal of physiological ecologists to be able to derive biochemical indices of an organism's physiological state, i.e. the use of RNA:DNA ratios (Westerman \& Holt 1994) and glycolytic enzymes (Childress \& Somero 1990). However, identifying a quantitative connection between the level of an enzymatic protein and an overall metabolic activity or physiological state is very difficult (Yang \& Somero 1996, Marsh et al. 2000). The complex interplay between numerous biochemical constituents has now focused our attention on to describing the integrative nature of metabolic regulation in order to accurately describe physiological states (Hochachka et al. 1998, Marsh et al. 2001).

Measuring physiological rate processes in small embryos and larvae has generally necessitated the pooling of many individuals into a sample measurement. However, improvements in assay technologies and methodologies are rapidly making measurements of rate processes in a single larva a real possibility. This new perspective on metabolic energy utilization in individual larvae could make an important contribution to our further understanding of the selective forces on reproductive strategies that have determined patterns of larval development and dispersal in marine invertebrates.

Acknowledgements. We thank C. Kopin and S. Park for advice and assistance with the care and culturing of the zoea larvae during this experiment. B. Glazer and Dr G. Luther provided the voltammetric calibrations for the oxygen optrodes. This work was supported in part by the National Science Foundation (OCE976866, PI: J. Sharp) providing a 'Research Experience for Undergraduate' fellowship to S.C.

\section{LITERATURE CITED}

Brendel PJ, Luther GWI (1995) Development of a gold amalgam voltammetric microelectrode for the determination of dissolved $\mathrm{Fe}, \mathrm{Mn}, \mathrm{O}_{2}$ and $\mathrm{S}^{(-\mathrm{II})}$ in porewaters of marine and freshwater sediments. Environ Sci Technol Libr 29:751-761

Childress JJ, Somero GN (1990) Metabolic scaling: a new perspective based on scaling of glycolytic enzyme activities. Am Zool 30:161-173

Emlet RB, Hoegh-Guldberg O (1997) Effects of egg size on postlarval performance: experimental evidence from a sea urchin. Evolution 51:141-152

Epifanio CE, Garvine RW (2001) Larval transport on the Atlantic continental shelf of North America: a review. Estuar Coast Shelf Sci 52:51-77

Epifanio CE, Dittel AI, Park S, Schwalm S, Fouts A (1998) Early life history of Hemigrapsus sanguineus, a non-indigenous crab in the Middle Atlantic Bight (USA). Mar Ecol Prog Ser 170:231-238

Forward RB (1986) A reconsideration of the shadow response of a larval crustacean. Mar Behav Physiol 12:99-113

Gnaiger E (1983) Calculation of energetic and biochemical equivalents of respiratory oxygen consumption. In: Gnaiger E, Forstner H (eds) Polarographic oxygen sensors. SpringerVerlag, Berlin, p 337-345

Hare JA, Cowen RK (1997) Size, growth, development, and survival of the planktonic larvae of Pomatomus saltatrix (Pisces: Pomatomidae). Ecology 78:2415-2431

Hart MW (1995) What are the costs of small egg size for a marine invertebrate with feeding planktonic larvae. Am Nat 146:415-426

Havenhand JN (1995) Evolutionary ecology of larval types. In: McEdward LR (ed) Ecology of marine invertebrate larvae. CRC Press, Boca Raton, p 79-122

Hawkins AJS, Day AJ (1999) Metabolic interrelations underlying the physiological and evolutionary advantages of genetic diversity. Am Zool 39:401-411

Hedgecock D, McGoldrick DJ, Manahan DT, Vavra J, Appelmans N, Bayne BL (1996) Quantitative and molecular genetic analyses of heterosis in bivalve molluscs. J Exp Mar Biol Ecol 203:49-59

Hentschel BT (1999) Complex life cycles in a variable environment: predicting when the timing of metamorphosis shifts from resource dependent to developmentally fixed. Am Nat 154:549-558

Heusner AA (1991) Size and power in mammals. J Exp Biol 160:25-54 
Hochachka PW, McClelland GB, Burness GP, Staples JF, Suarez RK (1998) Integrating metabolic pathway fluxes with gene-to-enzyme expression rates. Comp Biochem Physiol 120B:17-26

Hoegh-Guldberg O, Emlet RB (1997) Energy use during the development of a lecithotrophic and a planktotrophic echinoid. Biol Bull 192:27-40

Hoegh-Guldberg O, Manahan DT (1995) Coulometric measurement of oxygen-consumption during development of marine invertebrate embryos and larvae. J Exp Biol 198: 19-30

Holland LZ, McFall-Ngai M, Somero GN (1997) Evolution of lactate dehydrogenase-A homologs of barracuda fishes (genus Sphyraena) from different thermal environments: differences in kinetic properties and thermal stability are due to amino acid substitutions outside the active site. Biochemistry 36:3207-3215

Jørgensen DD, Vernberg WB (1982) Oxygen-uptake in a barnacle-scaling to body size from nauplius to adult. Can J Zool 60:1231-1235

Long GL (1975) The stereospecific distribution and evolutionary significance of invertebrate lactate dehydrogenases. Comp Biochem Physiol 55B: 77-83

Marsh AG, Manahan DT (1999) A method for accurate measurements of the respiration rates of marine invertebrate embryos and larvae. Mar Ecol Prog Ser 184:1-10

Marsh AG, Manahan DT (2000) Metabolic differences between 'demersal' and 'pelagic' development of the Antarctic sea urchin Sterechinus neumayeri. Mar Biol 137:215-222

Marsh AG, Leong PKK, Manahan DT (1999) Energy metabolism during embryonic development and larval growth of an Antarctic sea urchin. J Exp Biol 202:2041-2050

Marsh AG, Leong PKK, Manahan DT (2000) Gene expression and enzyme activities of the sodium pump during sea

Editorial responsibility: John Lawrence (Contributing Editor), Tampa, Florida, USA urchin development: implications for indices of physiological state. Biol Bull 199:100-107

Marsh AG, Maxson RE, Manahan DT (2001) High macromolecular synthesis with low metabolic cost in Antarctic sea urchin embryos. Science 291:1950-1952

McEdward LR (1997) Reproductive strategies of marine benthic invertebrates revisited: facultative feeding by planktotrophic larvae. Am Nat 150:48-72

McEdward LR, Morgan KH (2001) Interspecific relationships between egg size and the level of parental investment per offspring in echinoderms. Biol Bull 200:33-50

Moreno G, Hoegh-Guldberg O (1999) The energetics of development of three congeneric seastars (Patiriella Verrill, 1913) with different types of development. J Exp Mar Biol Ecol 235:1-20

Pechenik JA (1999) On the advantages and disadvantages of larval stages in benthic marine invertebrate life cycles. Mar Ecol Prog Ser 177:269-297

Pechenik JA, Wendt DE, Jarrett JN (1998) Metamorphosis is not a new beginning. BioScience 48:901-910

Sastry AN, Ellington WR (1978) Lactate dehydrogenase during the larval development of Cancer irroratus: effect of constant and cyclic thermal regimes. Experientia 34 308-309

Stokes MD, Somero GN (1999) An optical oxygen sensor and reaction vessel for high-pressure applications. Limnol Oceanogr 44:189-195

Westerman M, Holt GJ (1994) RNA-DNA ratio during critical period and early larval growth of the red drum Scalneopus ocellatus. Mar Biol 121:1-9

Yang TH, Somero GN (1996) Activity of lactate dehydrogenase but not its concentration of messenger RNA increases with body size in barred sand bass, Paralabrax nebullfer (Teleostei). Biol Bull 191:155-158

Submitted: December 13, 2000; Accepted: April 10, 2001

Proofs received from author(s): August 2, 2001 